This precaution is especially necessary for people who have to get up once or twice at night to pass urine. The act of micturition may acutely lower the blood pressure, either by the exertion of increased intra-abdominal pressure, or possibly by a spinal reflex from the bladder. Very hot baths are unwise, but a rough surface on the bottom of the bath and handles at the side help the person to get out safely. Showers may be safer and more economical.

The mainstay of treatment of severe postural hypotension is expansion of the blood volume, but this generally results in a rise in the supine as well as the standing blood pressure. If an elderly person has a distinctly raised blood pressure when supine, it is inadvisable to go much further than advising a reasonable amount of salt in the diet, lest postural hypotension is exchanged for congestive failure or, still worse, for pulmonary oedema. More heroic measures such as sympathomimetic drugs and antigravity suits are not as a rule necessary, but elastic stockings coming high up the legs may help to relieve symptoms in cases of mild incapacity.

1 Sjöstrand, R., Acta Medica Scandinavica, 1953, 145, 155.

2 Bannister, R., Ardill, L., and Fentem, P., Brain, 1967, 90, 725

sodstein, M., and Zeman, F. D., Fournal of Chronic Diseases, 1957, 6, 581,

- Johnson, R. H., Smith, A. C., Spalding, J. M. J., and Woollner, L., Lancet, 1965, 1, 731.

Caird, F. I., Andrews, G. R., and Kennedy, R. D., British Heart fournal, $\cdot 1973,35,527$.

- Kendell, R. E., and Marshall, J., British Medical fournal, 1963, 2, 344.

\section{Medical Officers' Prospects}

The voluntary recruitment of sufficient doctors to the armed Forces is always bound to be a source of worry to the Ministry of Defence. For they must offer a more attractive way of life than civilian practice or a level of pay that is irresistible. Yet the way of life, though it certainly does have its attractions, is also beset with uncertainties, and the level of pay, though intended to offer something more than civilian earnings, is unlikely ever to be thought generous. Partly because of these drawbacks the report of the Defence Medical Services Inquiry Committee ${ }^{1}$ published last week has to state that the scheme of recruitment on which it must rely-namely, medical cadetship-attracts too many men who are not strongly motivated towards the services and have no intention of staying.

This committee was appointed in April 1971 to review the arrangements for providing medical, dental, and nursing services for the armed Forces for peace and war, and of its many recommendations two groups stand out. The first of these is concerned with education, the second with the more efficient use of hospital resources.

Like practice in civilian life medical service in the Forces needs to be arranged so that doctors can continue to acquire professional education. But the difficulties confronting the medical officer are if anything greater than those the civilian doctor must overcome. Servicemen are of necessity a relatively healthy section of the population. The medical care of them, and in some stations of their families also, naturally entails a certain amount of conventional clinical practice. But preventive medicine must be a greater preoccupation of many medical officers than it is in civilian life. And the committee did indeed find that misgivings about their postgraduate training were the greatest source of anxiety-except the possible threat of an amalgamation of the defence medical services-to medical officers about their service life. Many felt afraid of falling behind their civilian contemporaries and thought that their opportunities for further education were left too much to chance.
The committee has sensibly devoted to this anxiety the attention it deserves and proposes a variety of measures to improve the organized programmes of training and study. Among them is a recommendation ${ }^{3}$ that service hospitals should take sufficient N.H.S. patients "to give a reasonably wide range of clinical experience." It recognizes the importance too of the medical officers receiving encouragement to undertake advanced training and being granted the time for it. However difficult postgraduate professional training may be to fit into the requirements imposed on the armed Forces, its necessity must be accepted from the top down if medical officers are to be recruited in the first place and properly utilized throughout their service thereafter.

When it comes to consider the provision of hospital services for the Forces the committee favours some fairly drastic reduction. It does not spend long on the idea, often proposed, of unifying the medical branches of the three Services. For apart from the resistance to it among the medical officers themselves, it is generally acknowledged that any such amalgamation would increase instead of diminish the speed of communication while the Royal Navy, Army, and R.A.F. remain separate commands. But when local circumstances are right co-operation between all three Services in running a hospital and in other ways is greatly to be encouraged. The report makes a number of recommendations on how this may be done including, for example, inter-service centres for psychiatry and plastic surgery. At the top it hopes to get more coordination by rejuvenating the Defence Medical Services Co-ordinating Committee, which at present meets only irregularly and somewhat ineffectually. But unless this body has authority and professional standing it could quickly become just another paper tiger.

Though the committee's main concern was not with pay, which is the responsibility of the Armed Forces Pay Review Body, it touches on an issue that deserves some comment. According to the report "there is overwhelming evidence, of which doctors are aware," that many general practitioners in civil life are earning more than the average of the $£ 5,575$ a year that is taken as a base for the calculation of the medical officers' pay. This point, it considers-as did the B.M.A. in its evidence to the committee, should be drawn to the attention of the Armed Forces Pay Review Body.

This body also issued a report ${ }^{2}$ last week, and its niggardly approach to medical officers' pay is unlikely to win it popularity. It recommends an average increase in pay of $£ 185$ a year and in doing so declares the figure to be based on the rates recommended by the Review Body's third report ${ }^{34}$ for the Health Service doctors, which the Government has accepted. The comparable figure in that report was $£ 250$ (less $£ 10$ for earnings outside the Health Service). The figure now proposed for Service doctors is thus $£ 65$ lower. The reason for this does not appear in the report but is believed to derive from a contention of the Government's that on the previous pay scale Service doctors had been overpaid in relation to the complex formula that relates their pay to the civilian scales. The whole question of the relationship of these pay scales needs thorough consideration, for on their being acceptable to Service doctors depends the functioning of the medical branches of the armed Forces.

\footnotetext{
1 Report of the Defence Medical Services Inquiry Committee (chairmen: first, Sir E. Compton, secondly, Sir C. Jarrett), Ministry of Defence. London, H.M.S.O., 1973 .

2 Review Body on Armed Forces Pay, Supplement to Second Report, Cmnd. 5450. London, H.M.S.O., 1973.

3 Review Body on Doctors' and Dentists' Remuneration, Third Report Cmnd. 5353. London, H.M.S.O., 1973.

${ }^{4}$ British Medical fournal, 1973, 3, 65.
} 